
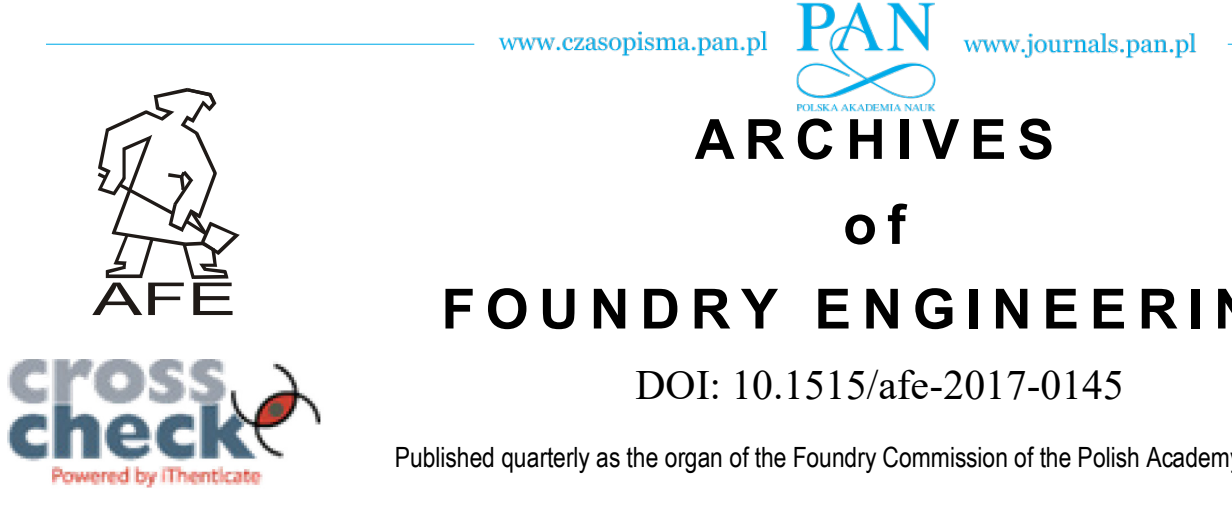

DE DE GRUYTER OPEN

FOUNDRY ENGINEERING

ISSN (2299-2944)

DOI: $10.1515 /$ afe-2017-0145

Volume 17

Issue $4 / 2017$

\title{
The Influence of the Microporosity on the Mechanical Properties of the AlZnMgCu Alloy, Based on the Numerical Analysis and Laboratory Trials
}

\author{
S. Pysz ${ }^{\text {a }}$, R. Żuczek ${ }^{\text {a, }}$, J. Piekło ${ }^{\text {b }}$, M. Maj ${ }^{\text {b }}$ \\ ${ }^{a}$ Foundry Research Institute, 73 Zakopiańska Str., 30-418 Cracow, Poland \\ ${ }^{\mathrm{b}}$ AGH University of Science and Technology, Faculty of Foundry Engineering, Department of Foundry Process \\ Engineering, 23 Reymonta Str., 30-059 Cracow, Poland \\ * Corresponding author. E-mail address: robert.zuczek@iod.krakow.pl
}

Received 23.03.2017; accepted in revised form 07.06.2017

\begin{abstract}
The ecological meanings clearly indicates the need of reducing of the concentration of the $\mathrm{CO}_{2}$ in the atmosphere, which can be accomplished through the lowering of the fuel consumption. This fact implies the research for the new construction solutions regarding the reduction of the weight of vehicles. The reduced weight of the vehicle is also important in the case of application of the alternative propulsion, to extend the lifetime of the batteries with the reduction of recharge cycles. The use of cast alloy AlZnMgCu compliant of plastic forming class $7 \mathrm{xxx}$ alloy, are intended to significantly reduce the weight of the structures, while ensuring high strength properties. The wide range of the solidification temperature, which is more than $150^{\circ} \mathrm{C}$, characterizes this alloy with a high tendency to create the micro and macro porosity. The study presents the relationship between the cooling rate and the area of occurrence and percentage of microporosity. Then the results were linked to the local tensile strength predicted in the simulation analysis. The evaluation of the microporosity was performed on the basis of the CT (computed tomography) and the analysis of the alloy microstructure. The microstructure analysis was carried out on test specimen obtained from the varying wall thickness of the experimental casting. The evaluation of the mechanical properties was prepared on the basis of the static tensile test and the modified low cycle fatigue test (MLCF).
\end{abstract}

Keywords: $\mathrm{AlZnMgCu}$ alloy, Microporosity, Mechanical properties, Low fatigue cycle test

\section{Introduction}

The use of $\mathrm{AlZnMgCu}$ alloys in manufacturing of highstrength construction remains still at the stage of preliminary tests and trials. $[1,2,3,4,5,6]$ The $7 \mathrm{xxx}$ series as alloys used in the plastic forming are characterized by high strengths of over 500 $\mathrm{MPa}$ and good plasticity up to $20 \%$. [7] The lack of metal forming (forging, rolling), eliminates one of the strengthening mechanisms which is squeeze hardening. In this case, the microstructure of the alloy is determined by the solidification process and the heat treatment. The high strength of $\mathrm{AlZnMgCu}$ alloys derives from the mechanism of the secretion of particles of intermetallic phases within comparatively widespread permanent solution $\alpha \mathrm{Al}$ (precipitation hardening). However, the dynamics of the separation and formation of phases, such as: $\eta\left(\mathrm{AlZn}_{2}\right)$, 
$\mathrm{T}\left(\mathrm{Al}_{6} \mathrm{CuMg}_{4}\right), \quad \mathrm{S}\left(\mathrm{Al}_{2} \mathrm{CuMg}\right)$, which significantly affect the properties of the alloy, depends on its chemical composition and solidification rate. [8] A higher zinc content has an impact on the increase in the strength of the alloy because it reduces the amount of T-phase precipitation. On the other hand the excessive amount of the zinc courses difficulties in obtaining a satisfactory elongation. The casting has usually a various wall thickness, with different solidification rates. This problem is particularly important in the analyzed alloys, since they have a wide solidification range of over $150^{\circ} \mathrm{C}$. This phenomenon is conducive to the formation of shrinkage porosity and shrinkagegas microporosity. The appropriate balance of the three essential elements $(\mathrm{Zn}, \mathrm{Mg}, \mathrm{Cu})$, and the reduction of impurities such as $\mathrm{Fe}$ and $\mathrm{Si}$, as well as the suitably selected heat treatment process, have an influence on the optimal structure and properties of the alloy.

\section{Research methodology}

The effect of the shrinkage porosity and microporosity on the properties of $\mathrm{AlZnMgCu}$ cast alloy was carried out on the test specimen obtained from the casting of a rocker arm using gravity casting technology in the sand mold (Figure 1). Castings were made of an alloy with the chemical composition presented in the Table 1 .

Table 1.

The chemical composition of $\mathrm{AlZnMgCu}$ alloy, [\%]

\begin{tabular}{cccccccccc}
\hline $\mathrm{Zn}$ & $\mathrm{Mg}$ & $\mathrm{Cu}$ & $\mathrm{Mn}$ & $\mathrm{Zr}$ & $\mathrm{Be}$ & $\mathrm{Ti}$ & $\mathrm{Fe}$ & $\mathrm{Si}$ & $\mathrm{Al}$ \\
\hline 5.8 & 1.98 & 1.53 & 0.17 & 0.13 & 0.14 & 0.1 & 0.08 & 0.06 & rest
\end{tabular}

The rocker arm with a net weight of about $8 \mathrm{~kg}$ was made in the sand mold. It is characterized by a non-uniform wall thickness, which facilitates the variation of solidification time. In addition, the gating system causes the formation of areas of extended solidification time. The pouring temperature was $710^{\circ} \mathrm{C}$.

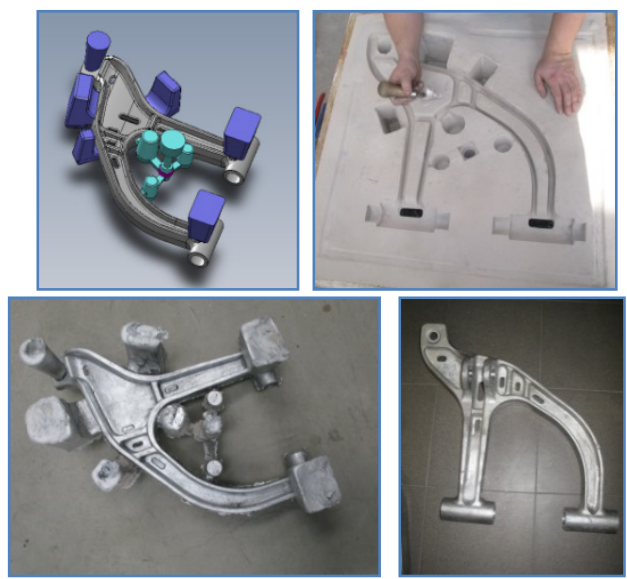

Fig. 1. The manufacturing steps of the construction of the rocker arm as sand casting technology: design model, preparation of the sand mold, casting after shaking out of the mold, casting after machining and heat treatment
Castings removed from the sand mold and after machining were subjected to heat treatment, T6 - solution and aging. The treatment characteristics are shown below:

- solution heat treating: $8.5 \mathrm{~h}$ at $450^{\circ} \mathrm{C}$ then, 1.5 at $500^{\circ} \mathrm{C}$,

cooling in water at $80^{\circ} \mathrm{C}$.

- aging: $30 \mathrm{~h}$ at $120^{\circ} \mathrm{C}$

The test specimen for microstructure and strength testing's were cut from the castings as shown in the Fig. 2. In order to determine the percentage of porosity and microporosity in the strength specimen, the computed tomography was used. The analysis of the microstructure of the specimen allowed to specify the microporosity in the selected area of casting. The experimentally appointed percentage of microporosity was compared with the numerical results of the simulation of the solidification. The use of a scanning electron microscopy (SEM) allowed to estimate the local percentages of the microporosity, grain size and the type of the breakthrough of the samples. The mechanical properties were evaluated on the basis of strength tests both in the static tensile test as well as in the modified low cycle fatigue. [9], [10], [11]
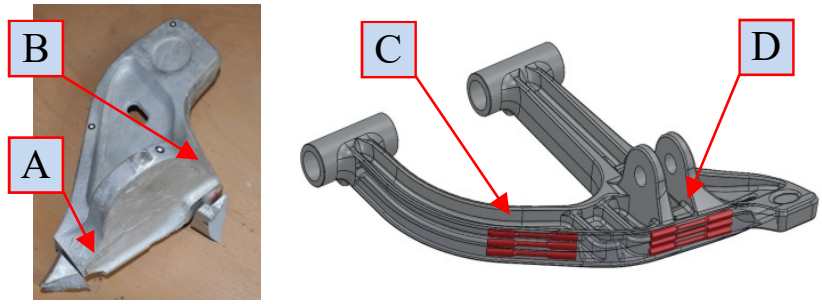

Fig. 2. Sampling areas for structural testing (A, B) and strength test $(\mathrm{C}, \mathrm{D})$

\section{Results of the numerical simulations, tomography and test of microstructure}

The numerical calculations of the cooling and solidification process of the rocker arm allowed to estimate the strength values and microporosities of the individual casting areas. In the numerical model, shrinkage microporosity is the same as the void created by dendrites (grains) and their interconnection. It is also bound to isolate areas that are no longer fed by liquid metal. The cause of gas microporosity is the presence of gas (mostly hydrogen) in the liquid metal.

Figure $3 \mathrm{~b}$ shows the image of durability variation across the whole casting, showing the areas from which test specimen (areas $\mathrm{C}$ and $\mathrm{D}$ ) were cut. Zone C, compared to the rest of the casting, has a significant higher strength of $442 \mathrm{MPa}$. In zone $\mathrm{D}$, where the riser is located, the presence of which significantly increases the solidification time, the strength is $380 \mathrm{MPa}$. 

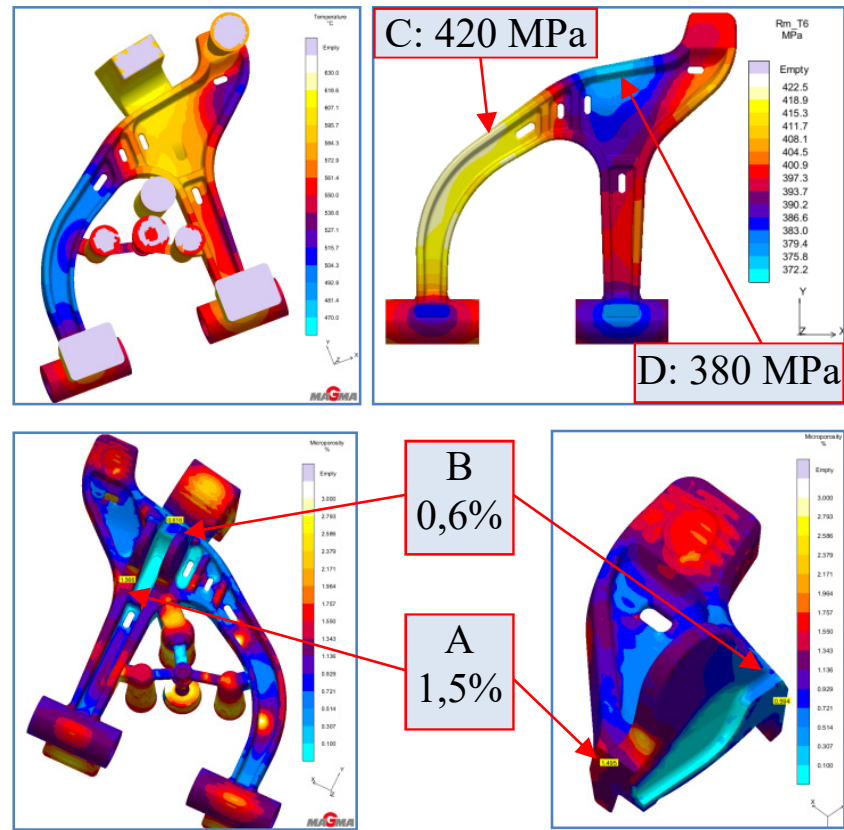

Fig. 3. The results of the numerical calculations of the rocker arm casting process: a) - temperature field at $284 \mathrm{sec}$ of solidification, b) - predicted strength $R_{m}$ in C and D areas, c) and d) - percentage of microporosity in areas $\mathrm{A}$ and $\mathrm{B}$

There is a large variation of the microporosity in the casting. In the area near to the feeder neck (area B) the percentage of the microporosity is significantly lower than in the area where the feeding effectively is lower (area A). This is confirmed by the microstructure analysis carried out on the samples obtained from the $\mathrm{A}$ and $\mathrm{B}$ areas of the cast (Figure 4). The estimated value of the microporosity in the area $\mathrm{A}$ is near $1.4 \%$, while in area $\mathrm{B}$ near $0.8 \%$.
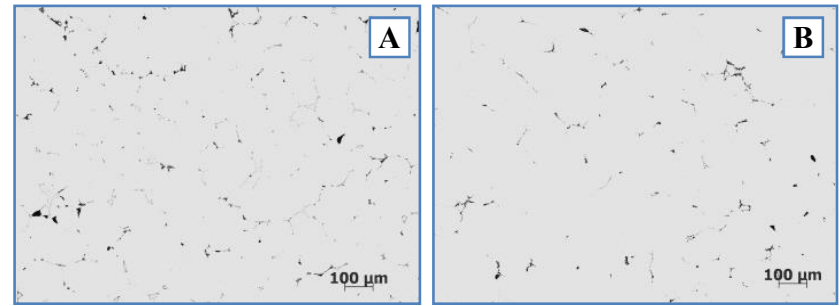

Fig. 4. Percentage of the microporosity in the areas:

$$
\mathrm{A}=1.4 \% \text { and } \mathrm{B}=0.8 \%
$$

Tables 2 and 3 shows the results of the strength tests of specimen from the castings areas $\mathrm{C}$ and $\mathrm{D}$ (Figures 2). The tables contain the values of $R_{m}$ (tensile strength), A (percentage elongation) and the number of test cycles.
Table 2.

The results of the strength tests of specimen from the $\mathrm{C}$ area of the casting

\begin{tabular}{cccc}
\hline Specimen & $\mathrm{R}_{\mathrm{m}}[\mathrm{MPa}]$ & $\mathrm{A}[\%]$ & Number of cycles \\
\hline 1 & 397 & 0,77 & 220 \\
2 & 444 & 0,74 & 248 \\
3 & 470 & 1,21 & 260 \\
4 & 467 & 1,28 & 244 \\
Average & 444 & 1,00 & 243 \\
\hline
\end{tabular}

Table 3.

The results of the strength tests of specimen from the D area of the casting

\begin{tabular}{cccc}
\hline Specimen & $\mathrm{R}_{\mathrm{m}}[\mathrm{MPa}]$ & $\mathrm{A}[\%]$ & Number of cycles \\
\hline 1 & 397 & 0,69 & 220 \\
2 & 361 & 0,60 & 200 \\
3 & 398 & 0,73 & 220 \\
4 & 399 & 0,65 & 220 \\
5 & 362 & 0,59 & 200 \\
Average & 383 & 0,65 & 212 \\
\hline
\end{tabular}

Fig. 5 shows picture from a computed tomography: a) cylindrical view of the sample after breaking; b) cross-section of the fractured sample with the porosity area initiating the rupture of the sample; c) cross-sections of samples with different angles to the direction of force reaction.
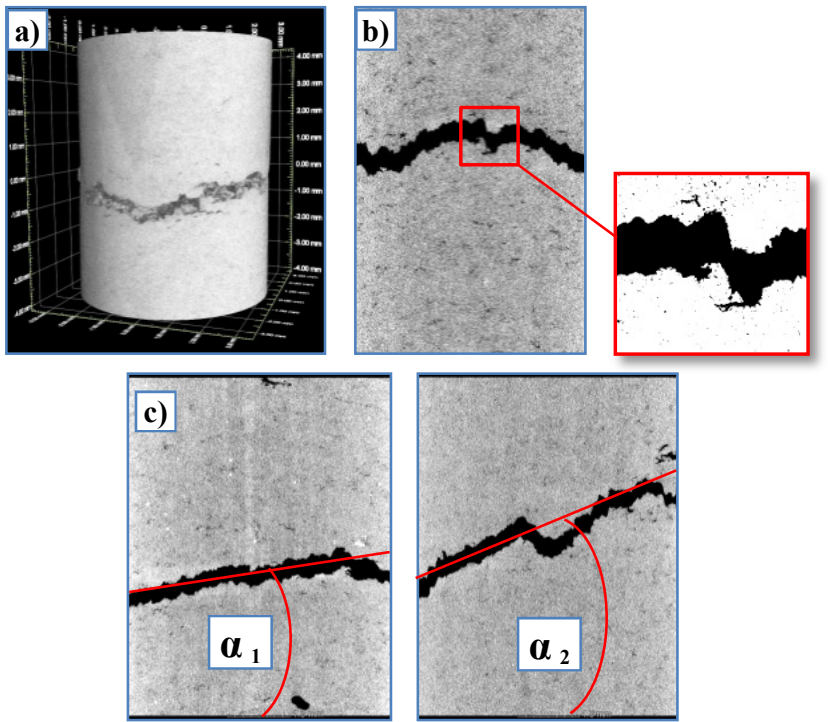

Fig. 5. The CT image of the breakthrough of the strength specimen

The images of the breakthroughs of the strength tests were analyzed using a scanning electron microscopy (Figure 6,7) to determine the type of breakthrough of the sample. Specimen breakthroughs indicate that the breakthrough occurs along the grain boundaries (Fig. 6b, 7a), in the areas of microporosity (Figure $7 b$ ), as well as inside the precipitations, e.g. silicon (Figure 6a, 6c).

Based on the analysis of CT images an estimated qualitative and quantitative distribution of the microporosity was done. 
The representative areas were located in the mid-section of the axial cross section of the samples, with a normalized area of $6 \mathrm{~mm}$. The analysis of CT images of the microporosities occurring in the areas are presented in Fig. 8.
The analysis of the CT images and the tensile strength led to attempt to establish a correlation between the volume fraction of microporosity in the breaking zone and the elongation and maximum deformation in the case of time-varying loads.

A comparison of comparative data is presented in Table 4.
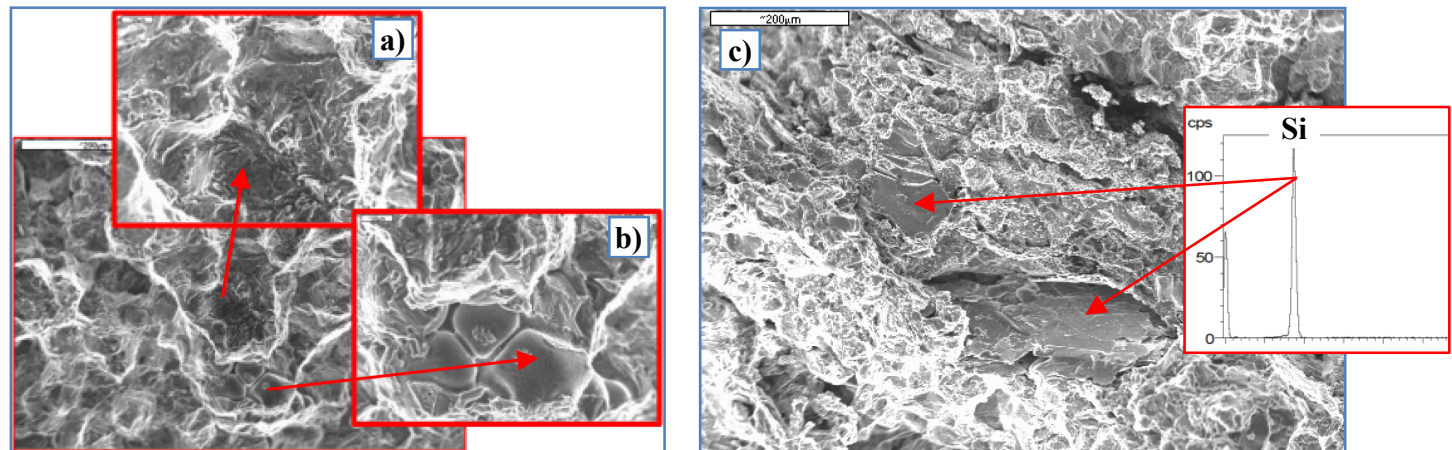

Fig. 6. SEM image: a) - breakthrough of broken grain, b) - separated grain surface after breaking, c) - split Si distribution in the structure
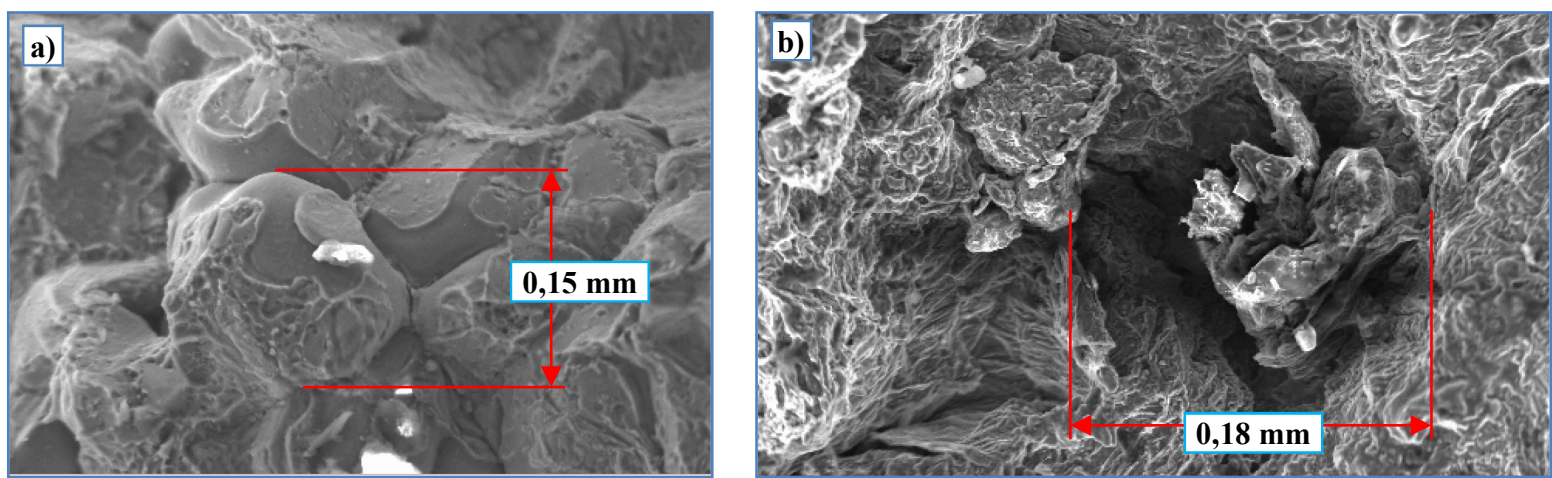

Fig. 7. SEM image, a) - separated grain surface covered with intermetallic phase, b) - porosity in the sample structure

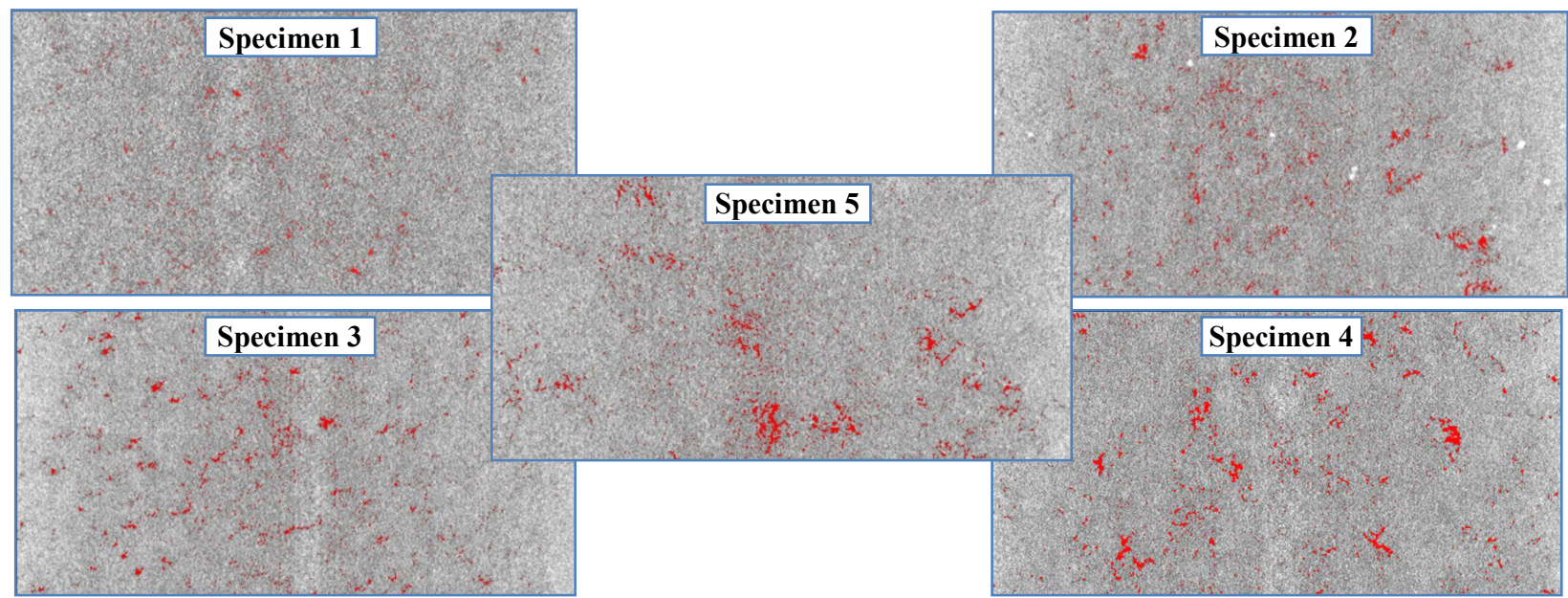

Fig. 8. Microporosity in selected cross sections of samples, determined on the basis of tomographic imaging analysis 
Table 4.

Experimentally determined strength and microporosity in the areas of the rocker arm

(A - percentage elongation, $\varepsilon_{p}-$ permanent elongation, $Z_{g_{0}}-$ fatigue strength, $E_{180}$ - modulus of elasticity for $\left.R_{m}=180 \mathrm{MPa}\right)$

\begin{tabular}{|c|c|c|c|c|c|c|c|c|c|}
\hline Specimen & $\begin{array}{c}\mathrm{R}_{\mathrm{m}} \\
{[\mathrm{MPa}]}\end{array}$ & $\begin{array}{c}\text { A } \\
{[\%]}\end{array}$ & $\begin{array}{l}\varepsilon_{\max } \\
{[\%]}\end{array}$ & $\begin{array}{c}\mathrm{E}_{180} \\
{[\mathrm{MPa}]}\end{array}$ & $\begin{array}{c}\varepsilon_{\mathrm{p}} \\
{[\%]}\end{array}$ & Microporosity [\%] & $\begin{array}{c}\mathrm{Z}_{\mathrm{go}} \\
{[\mathrm{MPa}]}\end{array}$ & $\begin{array}{c}\text { Number of } \\
\text { cycles }\end{array}$ & $\mathrm{Z}_{\mathrm{go}} / \mathrm{R}_{\mathrm{m}}$ \\
\hline 1 & 467 & 1,28 & 0,260 & 54554 & 0,125 & 0,836 & 174 & 244 & 0,372 \\
\hline 2 & 397 & 0,77 & 0,160 & 64109 & 0,116 & 1,667 & 134 & 220 & 0,337 \\
\hline 3 & 433 & 0,73 & 0,189 & 66649 & 0,077 & 1,735 & 151 & 240 & 0,348 \\
\hline 4 & 325 & 0,58 & 0,129 & 62567 & 0,045 & 2,114 & 105 & 167 & 0,323 \\
\hline 5 & 325 & 0,54 & 0,139 & 64991 & 0,028 & 2,229 & 112 & 179 & 0,344 \\
\hline
\end{tabular}

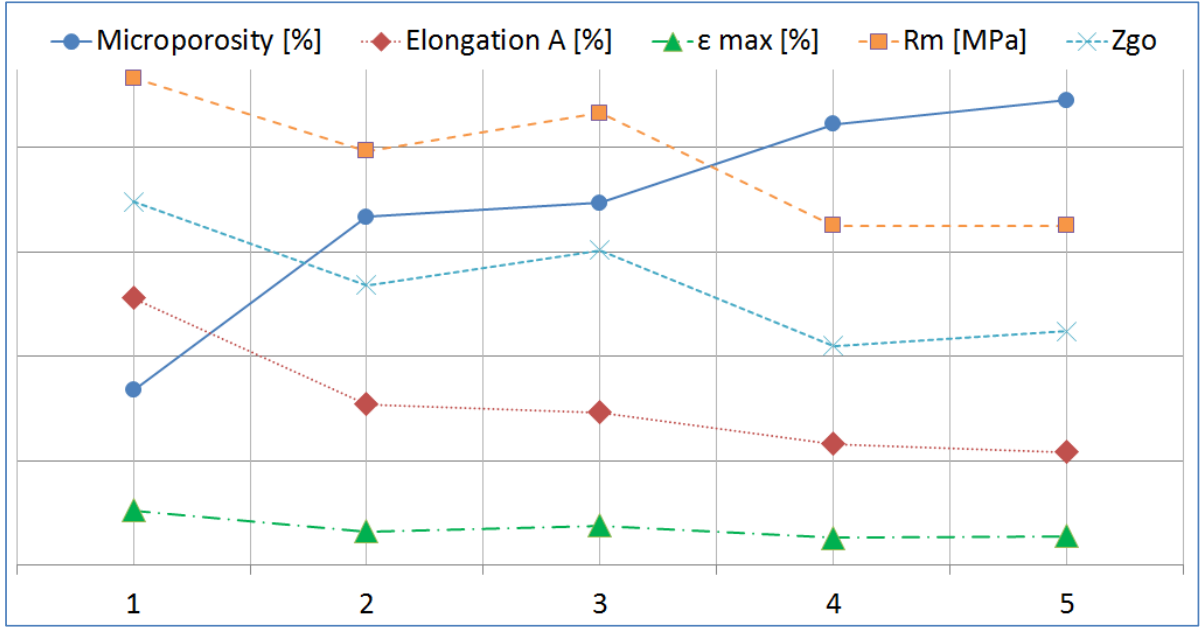

Fig. 9. Trend of the microporosity influence on the strength properties - Table 4

\section{Analysis of the results}

Obtained results regarding the distribution of the microporosity in the test specimen indicates a correlation between the microporosity and the elongation of the samples. Along with the decreasing of the microporosity in the specimen the elongation and the maximal acceptable displacement occurring in the time-dependent loading is rising (Table 4, Fig. 9). Such dependence cannot be observed in the case of tensile strength or Young's modulus. It has also been found that the number of load cycles decreases along with the increase of the microporosity. The number of time-dependent variable load for the test specimen causing destruction is relatively small and is varied from 200 to 260 cycles (Table 2,3,4). The assumption is if the influence of the precipitation hardening on the tensile strength $\mathrm{Rm}$ is greater, the fatigue strength ratio of the tensile strength is lower. According to [12] for the $7 \mathrm{xxx}$ series alloys which are subjected to plastic forging the ratio is small and reaches a value below 0,25. Estimated fatigue strength values for the test specimen used in the modified low cycle fatigue test indicate that the ratio for $\mathrm{AlZnMgCu}$ cast alloy is 0,34 . According to the study [13] for the alloy group used for the piston rods, the ratio is from 0,4 to 0,6 . These alloys are partially hardened during aging. It seems necessary to know the mechanism of fatigue failure of $\mathrm{AlZnMgCu}$ as a foundry alloy, since most of the research carried out in this field concerns the alloy after plastic processing.
The microstructure characteristics of the breakthrough section (Fig. 6, 7) shows that crack occurs in various zones: through the grain (Fig. 6a), on the grain surface (Fig. 6b, 7a), in the microporosity zone (Fig. 7b), on the surface of intermetallic precipitation (Fig. 7a). In addition, there is no individual plane in which the sample is destroyed. It has been observed that most of the cracks have a brittle fracture because the angle characterizing the plane of rupture to the plane perpendicular to the force is small (Fig. 5c). The specimen with the elongation of $1,28 \%$ (specimen 4, table 2) has the alignment angle of rapture significantly higher than other samples which indicates the occurrence of plastic rapture. The specimen has the highest tensile strength $(467 \mathrm{MPa})$. The effect of increased microporosity $(2.2 \%)$ on fracture initiation can be observed in specimen 5 (Table 4) for which the strength obtained is $325 \mathrm{MPa}$ and is the smallest of all tested specimens. Images obtained from the CT scanner (Fig. 5b) indicates that the breakage occurs on the border of microporosity.

The strength and microporosity distribution, as well as the absolute values obtained during the simulation and on the samples taken, show a good correlation. The microporosity in area A is higher than the microporosity in the area $\mathrm{B}$, which is confirmed by experimental and computer simulations. The microstructure of the samples taken from the area $\mathrm{A}$ and $\mathrm{B}$ and the calculated microporosities show that the absolute values are very similar (Fig. 3c, 3d, 4). The strength in the area $\mathrm{C}$ obtained in the computer simulation is near $420 \mathrm{MPa}$ whereas in the specimen obtained from the casting has the mean value of $440 \mathrm{MPa}$ 
(Fig. 3b). The specimens obtained from the casting area D show an average strength of $383 \mathrm{MPa}$ while numerical calculations show a value of approximately $380 \mathrm{MPa}$.

\section{Conclusion}

Based on the results, it is clear that the increase in the percentage of microporosity results in a decrease of the plastic properties of the alloy as well as the decrease in fatigue strength and maximum acceptable deformation in the case of variable time-dependent loads. The initiation of the fatigue cracks is observed in the area of the presence of the microporosity or on the matrix boundary separation, usually in the zone close to the outer surface of the specimen. The research has shown good comparability between the numerical simulation of the solidification process and the porosity with the $\mathrm{CT}$ analysis.

\section{Acknowledgements}

The work was realized from:

- Research and development project funded by the NCBiR no O R00009012: Development of construction and technology for the implementation of a hydro-active suspension on IED-resistant mobile vehicles. "Opracowanie konstrukcji oraz technologii wykonania zawieszenia hydroaktywnego w mobilnych pojazdach bezzałogowych odpornych na zagrożenie typu IED".

- Statutory activity no 11.11.170.318/task10: Numerical analysis of fatigue phenomena in foundry materials. "Numeryczna analiza zjawisk zmęczeniowych w tworzywach odlewniczych".

\section{References}

[1] Pysz, S., Żuczek, R., Czekaj, E., Piekło, J. \& Maj, M. (2016). Lightweight, high-strenght aluminium $\mathrm{AlZnMgCu}$ alloy castings. World Foundry Congress, 21-25 May 2016. Nagoya, Japan.

[2] Pysz, S., Czekaj, E., Żuczek, R., Maj, M. \& Piekło, J. (2016). Low cycle mechanical and fatigue properties of $\mathrm{AlZnMgCu}$ alloy. Archives of Foundry Engineering. 16(1), 55-60.

[3] Żuczek, R., Pysz, S., Maj, M. \& Piekło, J. (2016). Shaping the strength of cast rocker arm for special purpose vehicle. Archives of Foundry Engineering. 15(3), 95-98.

[4] Maj, M., Pysz, S., Piekło, J. \& Gazda, A. (2012). Fatigue testing of $\mathrm{AlZnMgCu}$ alloy used for parts of suspension system. Inżynieria Materiałowa. 33(6), 635-638.

[5] Druschitz1, A.P. \& Griffin, J. (2009). Advanced Cast Aluminum Alloys. Shape Casting: The 3rd International Symposium, The Minerals, Metals \& Materials Society, 2009, (pp. 53-60).

[6] David, M., Foley, R., Griffin, J. \& Monroe, Ch. (2016). Microstructural characterization and thermodynamic simulation of cast $\mathrm{AlZnMgCu}$ alloys. International Journal of Metalcasting. 10(1), 2-20.

[7] Druschitz, E.A. (2013). High strength cast aluminum alloy development. Doctoral dissertation, University of Alabama, Birmingham.

[8] Seong Taek Lim, Il Sang Eun \& Soo Woo Nam (2003). Control of Equilibrium Phases $(\mathrm{M}, \mathrm{T}, \mathrm{S})$ in the Modified Aluminum Alloy 7175 for Thick Forging Applications. Materials Transactions. 44(1), 181-187.

[9] Maj, M., Pietrzak, K. \& Piekło J. (2013). Modified low cycle method as a new criterion for a life fatigue assessment in foundry industry. Archives of Metallurgy and Materials. 2013 58(3), 877-881.

[10] Maj, M. \& Piekło J. (2016). Al 6082 and Al 7075 alloys under the modified low-cycle fatigue test. Metallurgy and Foundry Engineering. 42(1), 57-68.

[11] Gerard, D.A. \& Koss D.A. (1990): The dependence of crack initiation on porosity during low cycle fatigue. Material Science Engineering. A 129(1), 77-85.

[12] Czekaj, E. (2011). Nickel-free piston silumins of high dimensional stability (pp. 90 - 94). Kraków: Foundry Research Institute.

[13] Dymek, S. (2012). Modern aluminum alloys for plastic processing (pp. 81-89). Kraków: AGH 